\title{
Bile acid: a potential inducer of colon cancer stem cells
}

\author{
Lulu Farhana 1,3, Pratima Nangia-Makker ${ }^{1,2,3}$, Evan Arbit ${ }^{1}$, Kathren Shango ${ }^{1}$, Sarah Sarkar ${ }^{1}$, Hamidah Mahmud ${ }^{1}$, \\ Timothy Hadden ${ }^{1,3}$, Yingjie Yu ${ }^{1,3}$ and Adhip P. N. Majumdar ${ }^{1,2,3^{*}}$
}

\begin{abstract}
Background: Although the unconjugated secondary bile acids, specifically deoxycholic acid (DCA) and lithocholic acid (LCA), are considered to be risk factors for colorectal cancer, the precise mechanism(s) by which they regulate carcinogenesis is poorly understood. We hypothesize that the cytotoxic bile acids may promote stemness in colonic epithelial cells leading to generation of cancer stem cells (CSCs) that play a role in the development and progression of colon cancer.
\end{abstract}

Methods: Normal human colonic epithelial cells (HCoEpiC) were used to study bile acid DCA/LCA-mediated induction of CSCs. The expression of CSC markers was measured by real-time qPCR. Flow cytometry was used to isolate CSCs. T-cell factor/lymphoid-enhancing factor (TCF/LEF) luciferase assay was employed to examine the transcriptional activity of $\beta$-catenin. Downregulation of muscarinic 3 receptor (M3R) was achieved through transfection of corresponding siRNA.

Results: We found DCA/LCA to induce CSCS in normal human colonic epithelial cells, as evidenced by the increased proportion of CSCs, elevated levels of several CSC markers, as well as a number of epithelialmesenchymal transition markers together with increased colonosphere formation, drug exclusion, $A B C B 1$ and ABCG2 expression, and induction of M3R, p-EGFR, matrix metallopeptidases, and c-Myc. Inhibition of M3R signaling greatly suppressed DCA/LCA induction of the CSC marker ALDHA1 and also c-Myc mRNA expression as well as transcriptional activation of TCF/LEF.

Conclusions: Our results suggest that bile acids, specifically DCA and LCA, induce cancer stemness in colonic epithelial cells by modulating M3R and Wnt/ $\beta$-catenin signaling and thus could be considered promoters of colon cancer.

Keywords: Cancer stem cells, Colonospheres, ABCCB1, ABCG2, Deoxycholic acid, Lithocholic acid, Colonic epithelial cell, matrix metallopeptidases, Wnt/ $\beta$-catenin signaling

\section{Background}

Bile acids, the normal component of the luminal content, are needed for absorption of lipids, cholesterol, and fat-soluble vitamins, and are considered to be the regulators of intestinal epithelial homeostasis in the gastrointestinal (GI) tract [1]. It has long been known that certain secondary bile acids, secreted into the intestinal lumen and involved in fat absorption, can promote colon carcinogenesis [2-4]. Levels of bile acids are known to

\footnotetext{
* Correspondence: a.majumdar@wayne.edu

'Department of Veterans' Affairs Medical Center, 4646 John R, Detroit, Ml 48201, USA

${ }^{2}$ Karmanos Cancer Institute, Detroit, MI 48201, USA

Full list of author information is available at the end of the article
}

differ as a result of patho-physiological and environmental conditions including obesity, genetic traits, and lifestyle [4-8].

Epidemiological studies have revealed that the incidence of colorectal cancer (CRC) among populations migrating from low-incidence to high incidence countries changes rapidly. Within one generation, the incidence of CRC reached its highest level in people migrating from Japan to Hawaii [9]. This has been thought to be largely due to changes in diet. This inference comes from the observation that large increases in both meat and fat-enriched diet are associated with a rise in CRC [10]. Additionally, populations with high 
incidence of colon cancer also show an increase in fecal concentrations of bile acids [2, 11, 12]. These observations suggest that increased exposure of the colonic lumen to high levels of bile acids may play a role in the natural course of development of CRC and certain bile acids have been categorized as potential tumorpromoting agents, particularly for colon cancer [13].

The roles of cancer stem cells (CSCs) in the maintenance and progression of many types of cancer are now well accepted and continue to gain credibility as more evidence is uncovered. The CSC model proposes that a population of CSCs representing a small fraction of cancer cells exists within the tumor. These cells are able to self-renew and are capable of initiating carcinogenesis and sustaining tumor growth [14]. CSCs are identified by specific surface epitopes. In CRC, CD133, CD24, CD44, CD166, EpCAM, and ALDHA1 are reported as CSC markers [15-18]. Cells expressing these surface epitopes have the ability to form tumors at a much diluted concentration in SCID mice that histologically resemble the primary tumor from which they were derived [19]. Several stages of carcinogenesis in colon cancer comprise subpopulations of CSCs, which are responsible for tumor cell transformation, growth, and proliferation. Recently, it has been reported that the expression CSC markers CD44 and CD166, associated with KRAS mutation in primary colonic tumors, represent a higher risk of lymph node involvement by the tumor and development of liver and lung metastasis [18].

However, little information is available about the intrinsic/extrinsic factor(s) that may stimulate the generation of CSCs in the colonic mucosa. We hypothesize that certain bile acids, specifically acid (DCA) and lithocholic acid (LCA), most notorious for their cocarcinogenic activity [20-22], may induce CSCs in colonic mucosal cells leading to the development of CRC. Studies were conducted to test this hypothesis.

\section{Methods}

\section{Cell culture}

Normal human colonic epithelial cells (HCoEpiC) were purchased from ScienceCell Research Laboratories (Carlsbad, CA, USA) [23]. HCoEpiC were generated from human colonic tissues, cryopreserved at passage one, and delivered frozen. HCoEpiC are negative for HIV-1, HBV, HCV, mycoplasma, bacteria, and fungi. They can be stimulated to express HLA class II and intercellular adhesion molecules in vivo [24]. They have also been shown to respond to a broad array of cytokines and exhibit growth characteristics [25].

All experiments were performed within 10 passages after obtaining the cell line. The cells were maintained in Dulbecco's minimum essential medium (DMEM/F-12) supplemented with $10 \%$ fetal bovine serum (Invitrogen,
Grand Island, NY, USA) and 1\% gentamycin in a humidified incubator at $37{ }^{\circ} \mathrm{C}$ in an atmosphere of $95 \%$ air and $5 \%$ carbon dioxide.

\section{mRNA quantitation}

The cells, incubated with or without DCA or LCA, were subsequently treated with TRIzol reagent (Invitrogen, Carlsbad, CA, USA) as recommended by the manufacturer. RNA was isolated using the Rneasy Mini Kit (Qiagen).

For mRNA expression, cDNA was prepared with the SuperScript III First-Strand cDNA synthesis system for RT-PCR (Invitrogen) and analyzed in triplicate using the $2 \times$ SYBR Green PCR Master Mix (Applied Biosystem) and the ABI Prism 7500 sequence detection system. PCR consisted of denaturation at $95{ }^{\circ} \mathrm{C}$ for $10 \mathrm{~min}$ and 40 cycles of $95{ }^{\circ} \mathrm{C}$ for $15 \mathrm{sec}, 60{ }^{\circ} \mathrm{C}$ for $60 \mathrm{sec}$. Real-time qRT-PCR and analysis was performed in an Applied Biosystems 7500 Real Time PCR system. Ct values of mRNAs from each sample were calculated by normalizing with internal control $\beta$-actin. Each value represents the mean of three replicates.

The oligonucleotide primers were obtained from Integrated DNA Technology Inc. (Coralville, IA, USA). Matrix metallopeptidase (MMP) primers were the same as those reported by Xie et al. [26]. The primers for NCadherin, Slug, Twist, Vimentin, Zeb1, and Zeb2 were reported by Farhana et al. [27] and all other gene primers are presented in Table 1.

\section{Fluorescence-activated cell sorting of $\mathrm{CD} 44^{+} \mathrm{CD} 166^{-}$cells and spheroid formation Isolation of $\mathrm{CD}_{4} 4^{+} \mathrm{CD} 166^{-}$cells}

All reagents and instrumentation used for flow cytometry were from BD Biosciences (San Jose, CA, USA). $\mathrm{HCoEpiC}$ were grown to $70-80 \%$ confluence, trypsinized, and then washed with sorting buffer $(1 \times \mathrm{PBS}, 5 \%$ FCS). Cells were resuspended in $100 \mu \mathrm{l}$ sorting buffer and stained with fluorophore-conjugated antibodies as follows: with anti-CD45-perCP-Cy5.5 (clone), antiCD44-PECy7 (clone: G44-26), and anti CD166-PE (clone) or isotype-matched mouse IgG1-PerCP-Cy5.5, IgG2b-PE-Cy7, and PE-mouse IgG1 K (BD Pharmingen, San Diego, CA, USA). The stained cells were incubated for $1 \mathrm{~h}$ at $4{ }^{\circ} \mathrm{C}$, subsequently washed with PBS, and resuspended in $0.5 \mathrm{ml}$ sorting buffer. Compo-bead plus particles were stained in parallel, in accordance with the manufacturer's instructions, to provide compensation controls. $\mathrm{CD} 45^{+}$cells were excluded from analysis as described previously [28]. Flow cytometry was performed on a FACS Vantage SE SORP and data were analyzed with CellQuest. 
Table 1 Primer set for each gene

\begin{tabular}{ll}
\hline Gene & Sequences \\
\hline CD44 & Forward: 5'-AAGGTGGAGCAAACACAACC-3' \\
& Reverse: 5'-AACTGCAATGCAAACTGCAAG-3' \\
CD166 & Forward: 5'-TAGCAGGAATGCAACTGTGG-3' \\
& Reverse: 5'-CGCAGACATAGTTCCAGCA-3' \\
KLF4 & Forward: 5'-CCCAATTACCCATCCTTCCT-3' \\
& Reverse: 5'-ACGATCGTCTTCCCCTCTTT-3' \\
Nanog & Forward: 5'-GATTTGTGGGCCTGAAGAAA-3' \\
OCT4 & Reverse: 5'-CAGATCCATGGAGGAAGGAA-3' \\
SOX2 & Forward: 5'-AGTGAGAGGCAACCTGGAGA-3' \\
& Reverse: 5'-GCCGGTACAGAACCACACT-3' \\
C-MyC & Forward: 5'-AACCCCAAGATGCACAACTC-3' \\
& reverse: 5'-GCTTAGCCTCGTGGATGAAC-3' \\
EGFR & Forward: 5'-GGTGCTCCATGAGGAGACA-3' \\
& Reverse: 5'-CCTGCCTCTTTCCACAGAA-3' \\
B-catenin & Forward: 5'-CTITCGATACCCAGGACCAAG-3' \\
& Reverse: 5'-CAACTTCCCAAAATGTGCCC-3' \\
& Forward: 5'-TGGATGGGCTGCCTCCAGGTGAC-3' \\
& Reverse: 5'-ACCAGCCCACCCCTCGAGCCC-3' \\
& Forward: 5'-TCCTTCCTGGGCATGGAG-3' \\
& Reverse: 5'-AGGAGGGGCAATGATCTT-3' \\
\hline
\end{tabular}

\section{Formation of spheroids (colonospheres)}

The sorted $\mathrm{CD}_{4} 4^{+} \mathrm{CD} 166^{-}$cells from $\mathrm{HCoEpiC}$ were suspended in serum-free stem cell medium containing DMEM/F12 (1:1) supplemented with B27 (Life Technologies, Gaithersburg, MD, USA), 20 ng/ml EGF (Biomol International, Plymouth, PA, USA), $20 \mathrm{ng} / \mathrm{ml}$ fibroblast growth factor (Biomol International), and $100 \mu \mathrm{g} / \mathrm{ml}$ gentamycin. Approximately 150-200 cells/ well were seeded in an ultra-low-attachment 96-well plate (Corning Inc., Lowell, MA, USA).

After $24 \mathrm{~h}$, the cells were incubated in the absence (control) or presence of DCA or LCA for 12 days. Spheres formed were photographed and their size was measured utilizing an OLYMPUS CKX41 microscope supporting an Olympus DP72 digital camera and DP2BSW software (Olympus Soft Imaging Solutions $\mathrm{GmbH}$, Germany).

\section{Statistical analysis}

All statistics were performed using VassarStats web statistical software (Richard Lowry, Poughkeepsie, NY, USA). One-way analysis of variance (ANOVA) was performed to detect any differences between groups of control and bile acid-treated spheres. If the result of the ANOVA is significant $(P<0.01$ vs control), pairwise comparisons between the groups were made by a post- hoc test (Tukey's HSD procedure). The significance levels were set at $P<0.001, P<0.01$, and $P<0.05$.

\section{Hoechst 33342 dye exclusion assay}

HCoEpiC was treated with DCA and LCA $(100 \mu \mathrm{g})$ for 30 days. Single-cell suspensions were washed with PBS (three times) and stained with Hoechst 33342 or H342 ( $5 \mu \mathrm{g} / \mathrm{ml}$; Sigma Aldrich Inc., St Louis, MO, USA) for 45 min at $37{ }^{\circ} \mathrm{C}$ in Hank's Balanced Salt Solution (HBSS) (Invitrogen, Carlsbad), vortexing gently every $15 \mathrm{~min}$. The stained cells were collected, washed with PBS, and resuspended in $3 \mathrm{ml}$ of PBS containing $2 \mu \mathrm{g} / \mathrm{ml}$ of propidium iodide, and subsequently analyzed under a fluorescent microscope under UV and bright field. The number of viable cells that excluded dye was calculated as described previously [29].

\section{T-cell factor/lymphoid-enhancing factor luciferase assay}

In order to determine the activation of $\mathrm{Wnt} / \beta$-catenin signaling, the transcription factor $\mathrm{T}$-cell factor/lymphoid-enhancing factor (TCF/LEF)-luc reporter plasmid (Qiagen) was used in HCoEpiC. The cells were transfected with Cignal TCF/LEF-Luc reporter plasmid (SA Biosciences, Frederick, MD, USA) using lipofectamine 3000. TCF/LEF transfected cells were treated with bile acids for $48 \mathrm{~h}$ after $24 \mathrm{~h}$ post transfection. Cells were harvested and analyzed for TCF/LEF activity using a luciferase assay kit (Promega-Biosciences, San Luis Obispo, CA, USA) according to the manufacturer's instruction and the activity was measured on a BioTeK Synergy HT microplate reader.

\section{Western blot and immunoprecipitation}

For tyrosine phosphorylation studies of epidermal growth factor receptor (EGFR), the cells were grown in serum-free medium and treated with bile acids for $48 \mathrm{~h}$, then lysed using lysis buffer ( $25 \mathrm{mM}$ Tris- $\mathrm{Cl}(\mathrm{pH} 8.0)$, $150 \mathrm{mM} \mathrm{NaCl}, 0.2 \%$ nonidet P-40, 10\% glycerol $10 \mathrm{mM}$ $\mathrm{NaF}, 8 \mathrm{mM}$ glycerophosphate, $0.2 \mathrm{mM} \mathrm{Na} \mathrm{VO}_{4}, 1 \mathrm{mM}$ DTT, and $10 \mathrm{l} / \mathrm{ml}$ protease inhibitor cocktail; Sigma Aldrich).

For immunoprecipitation of protein(s), the cell lysates containing $0.3 \mu \mathrm{g}$ protein were incubated with $1 \mu \mathrm{g}$ of the anti-EGFR antibody (Santa Cruz Biotechnology) in a total volume of $500 \mu \mathrm{l}$ lysis buffer overnight at $4{ }^{\circ} \mathrm{C}$. Then $25 \mu$ l Protein G-Sepharose 4 Fast Flow beads (GE Healthcare Biosciences, Pittsburgh, PA, USA) added to each lysate and shaken for $2 \mathrm{~h}$ at $4{ }^{\circ} \mathrm{C}$. EGFR immunobeads were washed with lysis buffer containing protease inhibitors, and $20 \mu$ l loading buffer was added to each sample before boiling for $5 \mathrm{~min}$. Western blot analyses were performed as described previously [30]. 


\section{Silencing of muscarinic 3 receptor}

Human 4 unique 29mer shRNA duplexes targeting muscarinic 3 receptor (M3R), synthesized by Integrated Technology (IDT) using the TriFectamine kit, were utilized for silencing M3R. The gene silencing target sequences were from the coding sequence [PubMed:NM_000740] (CHRM3) and siRNA sequences, 5'-GTCATCAGCTTT GACAGATACTTTT-3' (si-M3RT2) and 5'-GGGTCA TTTCAATGAATCTGTTTACG-3' (si-M3RT3). The scrambled sequences of siRNA were used as a control. M3R siRNA duplexes were transfected transiently in HCoEpiC using lipofectamine 3000 (Invitrogen). Bile acid $(100 \mu \mathrm{M})$ was added after $24 \mathrm{~h}$ of post transfection and cells were harvested $72 \mathrm{~h}$ post transfection for mRNA quantitation and TCF/LEF activity.

\section{Immunofluoresence}

For $\beta$-catenin immunostaining, $\mathrm{HCoEpiC}$ cells were grown on an eight-chambered slide overnight. DCA/ LCA $(100 \mu \mathrm{M})$ were then treated with cells for $24 \mathrm{~h}$ and incubated for $72 \mathrm{~h}$. Cells were fixed with paraformaldehyde for $15 \mathrm{~min}$, washed three times with PBS, and then cells were permealized with ice-cold methanol for $5 \mathrm{~min}$ and washed three times with PBS. Cells were blocked with 5\% normal goat serum in PBS at room temperature for $1 \mathrm{~h}$ and then incubated with anti- $\beta$-catenin antibody (1:100 dilution; Cell Signaling) overnight at $4{ }^{\circ} \mathrm{C}$. After washing with $1 \times \mathrm{PBS}$, cells were incubated with antirabbit IgG-FITC conjugate (1:100 dilution) antibody for $30 \mathrm{~min}$ at room temperature. Cells were washed with PBS and then placed on cover slips with prolong gold antifade reagent containing DAPI (Cell Signaling Technology, Boston, MA, USA). Cells were photographed utilizing an Olympus microscope and an Olympus microscope digital camera with DP2-BSW software.

\section{Results}

\section{Bile acid induction of CSCs}

The primary objective of the current investigation is to determine whether bile acids, specifically DCA and/or LCA, would induce CSCs in colonic epithelial cells.

In the first set of experiments, we examined the changes in expression of several CSC markers as well as the proportion of CSCs in $\mathrm{HCoEpiC}$ following exposure to DCA or LCA for $72 \mathrm{~h}$. We observed that both DCA and LCA caused a marked 2-fold to 40-fold increase in the mRNA levels of CSC markers CD44, CD166, and ALDHA1 in HCoEpiC when compared with the control (Fig. 1a-c). However, LCA was found to be more effective than DCA in inducing the expression of these markers (Fig. 1a). In addition, the proportion of CD44positive and CD166-positive populations was found to be markedly higher in DCA-treated or LCA-treated cells, compared with the corresponding vehicle-treated control (Fig. 1d). These observations suggest that DCA and LCA can induce CSCs in colonic epithelial cells. To further investigate this issue, we examined the ability of DCA and LCA to stimulate spheroid formation by HCoEpiC, a property common to both normal and CSCs. To conduct this investigation, we isolated the $\mathrm{CD} 44^{+} \mathrm{CD} 166^{-}$phenotype from $\mathrm{HCoEpiC}$ by flow cytometry. This CSC phenotype was found to be a predictor of colonic adenoma [27, 28]. Cells were incubated after 12 days in stem cell media in the absence or presence of DCA or LCA. Incubation in stem cell media is known to kill epithelial cells but not stem cells/CSCs. Indeed, after 5-6 days of incubation, some cells began to form spheroids (surrogate tumors) in the absence or presence of bile acids. However, at the end of the 12-day incubation period, the size of the spheroids formed by the $\mathrm{CD} 44^{+} \mathrm{CD} 166^{-} \mathrm{CSC}$ phenotype of $\mathrm{HCoEpiC}$ in the presence of DCA or LCA was found to be markedly greater than those formed in the absence of bile acids (controls) (Fig. 1e). At 12 days, the DCA-treated and LCA-treated spheroids also showed the required integrity of spheroids. These observations further suggest that bile acids induce stemness in normal human epithelial cells.

Like normal stem cells, CSCs exhibit self-renewal in a de-differentiated state, pluripotency, but form tumors with a very small number of cells [31]. Four key transcription factors, OCT4 (POU class 5 homeo box 1), KLF4 (Kruppel like factor 4), SOX2 (SRY-box 2), and $\mathrm{c}-\mathrm{Myc}(\mathrm{v}-\mathrm{myc}$ avian myelocytomatosis viral oncogene homolog) (OKSM), have been identified as pluripotency genes in CSCs. OKSM have been shown to induce dysplasia and tumorigenesis in vivo [31-36]. In view of this, we examined the expression of KLF4, Nanog, OCT4, and SOX2 in HCoEpiC in response to DCA/LCA. As has been observed for CSC surface epitopes, the expression of KLF4, Nanog, OCT4, and SOX2 was also significantly elevated following incubation for 7 days with $100 \mu \mathrm{M}$ DCA or LCA, when compared with the corresponding control (Fig. 2a). These increases were accompanied by concomitant increases in the expression of N-cadherin, Slug, Twist, Vimentin, Zeb1, and Zeb2 (Fig. 2b) which are considered to be markers of epithelial-mesenchymal transition (EMT), cells that are thought to represent CSCs [37-39]. Taken together, the results suggest that DCA or LCA is able to transform colonic epithelial cells into CSCs.

To further determine whether DCA or LCA would indeed transform colonic epithelial cells to CSCs, the next set of experiments was conducted. One of the primary properties of CSCs, as opposed to adult stem cells, is their ability to resist chemotherapy because of increased drug efflux capacity [40]. We observed that the 


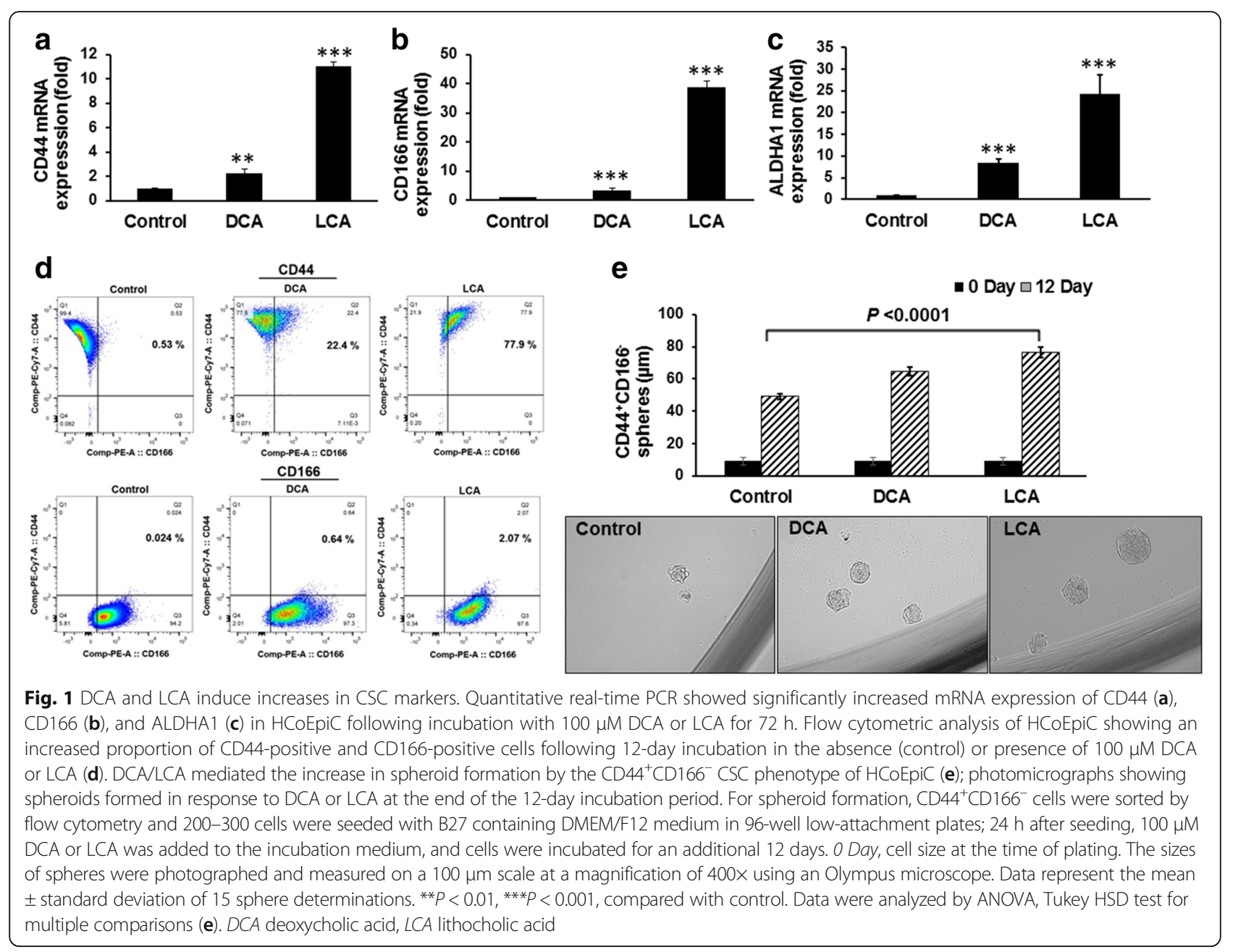

proportion of $\mathrm{HCoEpiC}$ that excluded Hoechst 33342 dye was greatly increased (2-fold to 3-fold) following 30 days of exposure to $100 \mu \mathrm{M}$ of DCA or LCA, when compared with the control (Fig. 3a). One of the reasons for increased drug exclusion by cells is thought to be due to the elevated levels of $\mathrm{ABC}$ transporter proteins ABCB1 (ATP binding cassette subfamily B member 1) and ABCG2 (ATP binding cassette subfamily $G$ member 2 ), members of the superfamily of ATP-binding cassette $(\mathrm{ABC})$ transporters, whose primary function is to transport various molecules across the intracellular and extracellular membranes [40]. In HCoEpiC cells, we found LCA treatment for 18 days to cause a significant 1.5-fold to 2-fold increase in ABCB1 and ABCG2 mRNA levels when compared with the control (Fig. 3b, c). A similar phenomenon was also noted following 30-day exposure of HCoEpiC to DCA or LCA (data not shown). These results indicate the induction of CSCs in $\mathrm{HCoEpiC}$ following a prolonged exposure to the secondary bile acids, DCA or LCA.

To further determine whether the presence of CSCs in $\mathrm{HCoEpiC}$ would lead to the processes of carcinogenesis, the following experiments were conducted. Earlier studies have reported that secondary bile acids such as LCA activate M3R and that this activation is important for colon cancer progression $[41,42]$. In view of this, we examined the expression of M3R in HCoEpiC following exposure to DCA or LCA. We found DCA or LCA to induce an 8-fold to 12-fold increase in M3R mRNA levels in HCoEpiC, when compared with the control (Fig. 4a).

To further determine the role of M3R in DCA/LCA regulation of CSCs, we downregulated the receptor in HCoEpiC by the corresponding siRNAs. Two different siRNAs for M3R (si-M3RT2 and si-M3RT3) were utilized. Transfection of HCoEpiC with either si-M3RT2 or siM3RT3 resulted in a marked $80-85 \%$ reduction of the receptor (Fig. 4b), accompanied by a significant reduction in the expression of ALDHA1 and c-Myc, when compared with the corresponding control (Fig. 4c). Additionally, we observed that while DCA caused a significant (100-300\%) increase in the expression of ALDHA1, CD166, and cMyc in HCoEpiC, no such increase by DCA could be observed in cells when M3R was downregulated (Fig. 4d-f). 


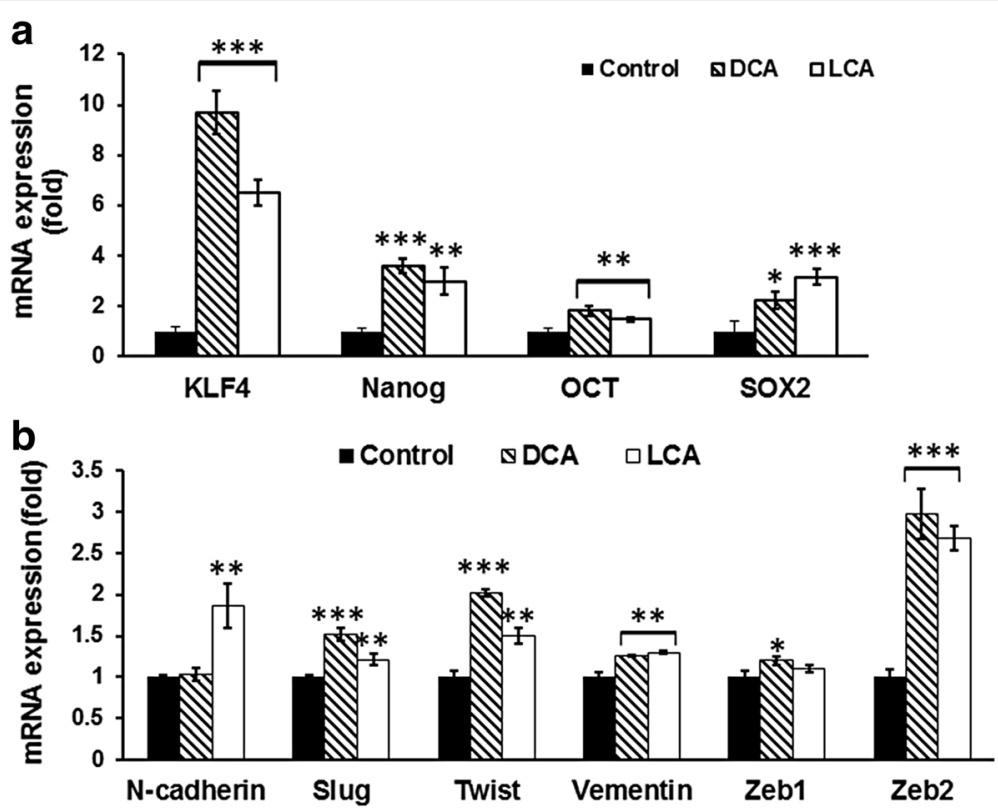

Fig. 2 Exposure of DCA/LCA in HCoEpiC increased the expression of pluripotency genes. Levels of mRNA encoding the pluripotency genes KLF-4, Nanog, OCT4, and SOX2 was significantly higher in cells incubated with DCA or LCA than control cells (a). Likewise, expression of EMT regulators $\mathrm{N}$-Cadherin, Slug, Twist, Vimentin, Zeb1, and Zeb2 was also increased in response to $100 \mu \mathrm{M}$ DCA or LCA (b). Results expressed as mean \pm standard deviation of three separate experiments. ${ }^{*} P<0.05,{ }^{*} P<0.01$ and ${ }^{* *} P<0.001$. DCA (deoxycholic acid), LCA (lithocholic acid)

Wnt/ $\beta$-catenin signaling plays a pivotal role not only in maintaining homeostasis of intestinal crypt but also in regulating proliferation of colon CSCs [43-45]. We have observed that in HCoEpiC, DCA, and LCA not only stimulated the expression of $\beta$-catenin, but also the Wnt/ $\beta$-catenin signaling, as evidenced by the induction of transcriptional activity of TCF/LEF (Fig. 5a, b).

The Wnt/ $\beta$-catenin signaling pathway leads to dephosphorylation, stabilization, and nuclear translocation of $\beta$-catenin. Nuclear $\beta$-catenin forms a complex with TCF/LEF family transcription factors and acts as a coactivator to express target genes in canonical Wnt signaling pathway such as CCND1 and MYC $[46,47]$. We found in HCoEpiC that exposure to DCA/LCA resulted in a marked 2-fold to 3-fold increase in the expression of $\beta$-catenin, accompanied by a marked induction of transcriptional activity of TCF/LEF, when compared with the corresponding controls (Fig. 5a, b). We have also observed increased nuclear localization of $\beta$-catenin in $\mathrm{HCoEpiC}$ following exposure to DCA or LCA (Fig. 5c). These increases were also accompanied by a 12 -fold to 15 -fold increase in the level of c-Myc (Fig. 5d), one of the downstream effectors protein of $\mathrm{Wnt} / \beta$-catenin signaling [47-49]. c-Myc also regulates stemness in CSCs [31]. In the presence of si-M3R-RNA, DCA-mediated stimulation of transcriptional activity of TCF/LEF was decreased by about $45 \%$ (Fig. $5 \mathrm{e}$ ), indicating a role for M3R in regulating bile acid induction of carcinogenesis in colonic epithelial cells.
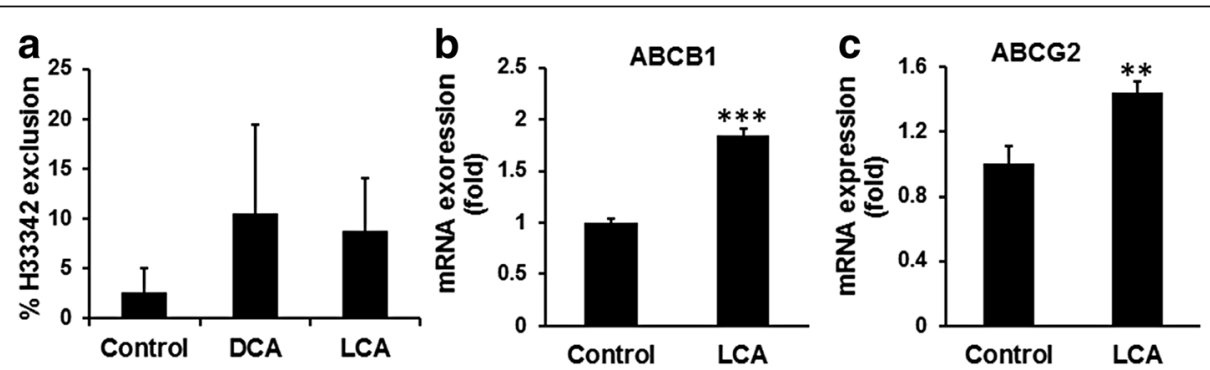

Fig. 3 DCA/LCA induction of drug exclusion in HCoEpiC. Ability of HCoEpiC cells to exclude Hoechst dye (H33342) was greatly increased following 30-day incubation with DCA or LCA (a). Likewise, the expression of ABCB1 and ABCG2 was also increased in HCoEpiC cells following 18-day exposure to $50 \mu \mathrm{M} \mathrm{LCA} \mathrm{(b,} \mathrm{c).} \mathrm{Controls} \mathrm{contained} \mathrm{the} \mathrm{appropriate} \mathrm{vehicle.} \mathrm{Data} \mathrm{represent} \mathrm{the} \mathrm{mean} \pm$ standard deviation of three separate determinations. ${ }^{* *} P<0.01$ and ${ }^{* * *} P<0.001$ Statistical significance determined by $t$ test. DCA (deoxycholic acid), LCA (lithocholic acid) 


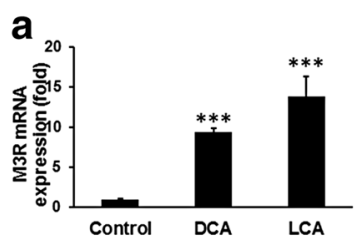

d

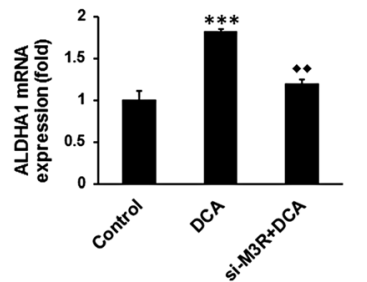

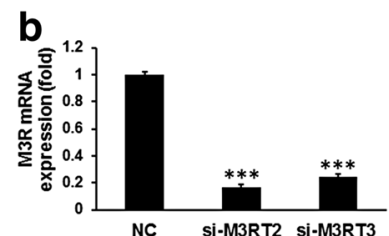

$\mathbf{e}$

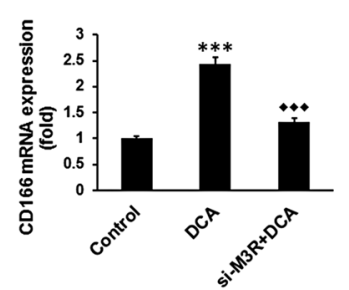

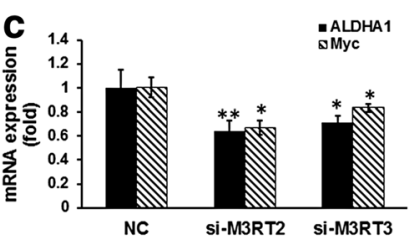

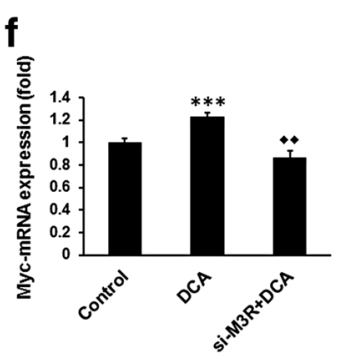

Fig. 4 DCA/LCA induction of CSC phenotypic characters in HCoEpiC is mediated by M3R and knockdown of M3R decreased ALDHA1, c-Myc, and TCF/LCF activity in cells treated with DCA. Induction of M3R in HCoEpiC following incubation with $100 \mu \mathrm{M}$ DCA or LCA after $72 \mathrm{~h}$ (a). Downregulation of M3R in cells following transfection with either of two siRNAs (si-M3RT2 and si-M3RT3) for M3R (b). ALDHA1 and c-Myc expression is reduced in M3R-downregulated cells (c). Suppression of DCA-induced stimulation of ALDH1, CD166, and c-Myc expression in M3R-downregulated cells (d-f). Data represent the mean \pm standard deviation of three separate determinations. ${ }^{*} P<0.05$, ${ }^{*} P<0.01$, and ${ }^{* * *} P<0.001$, compared with the control. DCA (deoxycholic acid), LCA (lithocholic acid)

Muscarinic agonist-induced cell proliferation is mediated by cross-talk between high expression of M3R and EGFRs in human colon cancer cells and M3R activation causes a marked enhancement in MMPs [50, 51]. We also found a similar phenomenon in $\mathrm{HCoEpiC}$; DCA and LCA not only produced a marked increase in the expression of EGFR but also greatly activated EGFR, as determined by tyrosine phosphorylation (activated form; measured using ${ }^{\text {Tyr }}$ 992EGFR antibody) (Fig. 6a, b). This increase was associated with a marked rise in MMP mRNAs, MMP1, MMP3, and MMP10 mRNA in HCoEpiC (Fig. 6c).
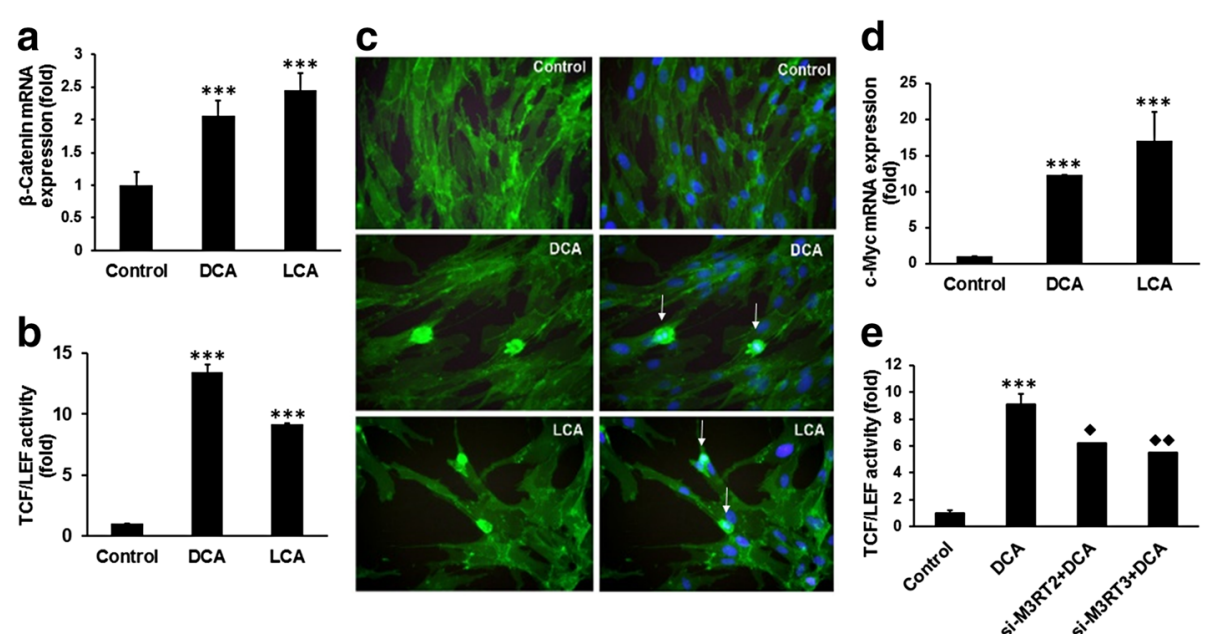

Fig. 5 Bile acids induce Wnt- $\beta$-catenin signaling pathways and increase the expression of the target gene c-Myc in HCoEpiC. Real-time qPCR showing an increased expression of $\beta$-catenin mRNA in HCoEpiC cells following 72-h incubation in the presence of $100 \mu \mathrm{M}$ DCA or LCA (a). Induction of transcriptional activity of TCF/LEF in HCoEpiC in response to $100 \mu \mathrm{M}$ DCA or LCA treatments for $72 \mathrm{~h}$ (b). Photomicrographs showing increased nuclear localization of $\beta$-catenin in HCoEpiC following $72 \mathrm{~h}$ incubation with $100 \mu \mathrm{M}$ DCA or LCA; controls were incubated with an equivalent volume of the vehicle (c): left panel , $\beta$-catenin immunostained cells; right panel, merged photograph of $\beta$-catenin and nucleus stained with DAPI; arrow, nuclear localization of $\beta$-catenin in cells. Increased expression of c-Myc in HCoEpiC following 72-h exposure to $100 \mu M$ DCA or LCA (d). DCA LCA-mediated induction of transcriptional activity of TCF/LEF is greatly suppressed in M3R-downregulated HCoEpiC (e). Cells were photographed on a $100 \mu \mathrm{m}$ scale at a magnification of 400x. Results expressed as mean \pm standard deviation of three separate experiments. ${ }^{*} P<0.05$, ${ }^{* *} P<0.01$ and ${ }^{* * *} P<0.001$. DCA (deoxycholic acid), LCA (lithocholic acid), TCF/LEF (T-cell factor/lymphoid-enhancing factor). Diamonds represent significant reduction in M3R down-regulated cells in response to DCA compared to those without siM3R transfected cells 


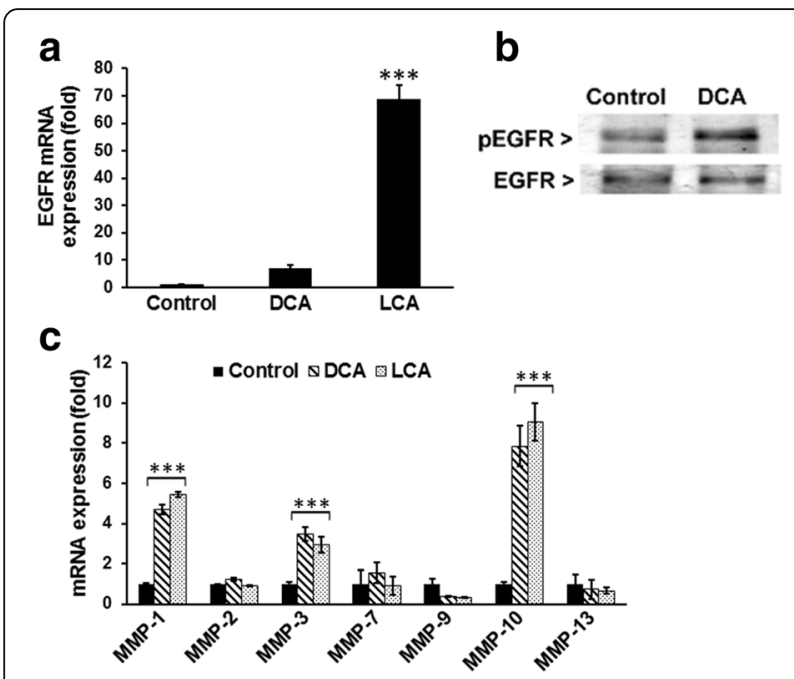

Fig. 6 DCA/LCA increased the expression and activation of EGFR in HCoEpiC. Real-time qPCR showing increased expression of EGFR mRNA in cells in response to DCA and LCA (a). Western blot analysis indicates increased tyrosine phosphorylation (Y992) of EGFR in response to DCA (b). Real-time $\mathrm{gPCR}$ showing changes in the expression of the MMPs in cells in response to DCA or LCA (c). Results represent the mean of three separate determinations \pm standard deviation. ${ }^{* *} P<0.001$, compared with control. DCA (deoxycholic acid), EGFR (epidermal growth factor receptor), LCA (lithocholic acid), MMP (matrix metallopeptidase)

\section{Discussion}

Higher levels of secondary bile acids in feces and an increased incidence of colorectal cancer (CRC) were observed in patients that consumed high-fat/low-fiber diets [52-54]. Several epidemiological studies have also revealed an association between bile acids and CRC. The presence of CRC has been associated with a higher fecal LCA/DCA ratio and with elevated fecal secondary bile acids levels [53-56]. Although the precise mechanism(s) by which bile acids induce colon carcinogenesis is poorly understood, DCA and chenodeoxycholic acid (CDCA)mediated genotoxicity in normal human colonic epithelial cells as well as in tumor cells has been found to be due to DNA oxidative damage [57]. Increased apoptosis and other forms of toxicity have been observed in the liver following prolonged exposure to high levels of bile acids [58-61].

The hydrophobic bile acids DCA and LCA appear to be the most significant bile acids with respect to the development of CRC [5]. Data from several in-vitro and in-vivo studies also support this contention. Exposure of normal colonic epithelial cells to DCA has been shown to cause mitotic aberrations that are precursors of aneuploidy and are indicators of genome instability [6].

Our current observation that the proportion of CSCs as well as the expression of several markers of CSCs, formation of spheroids (colonospheres), and the levels of pluripotency markers KLF4, Nanog, OCT4, and SOX2 and
EMT markers such as Vimentin, Slug, Twist, and Zeb2 are greatly augmented in $\mathrm{HCoEpiC}$ in response to DCA or LCA suggests that these secondary bile acids induce the formation of CSCs. Further support for this inference comes from the observation that drug exclusion, an inherent property of CSCs as determined by exclusion of $\mathrm{H} 33342$, is also markedly augmented in normal human colonic epithelial cells following prolonged exposure to DCA or LCA. The fact that the expression of multiple drug resistance (MDR) transporter genes ABCB1 and ABCG2 is also augmented by DCA and LCA provides additional support to our contention that the secondary bile acids, specifically DCA and LCA are able to induce transformation of normal colonic epithelial cells to CSCs, which are known to play a pivotal role in the development and progression of many malignancies, including CRC [62].

Bile acid-mediated induction of colon carcinogenesis appears to be regulated by the muscarinic cholinergic family of G-protein-coupled receptor, which consists of five subtypes M1R-M5R. Results from earlier studies suggest that secondary bile acids such as LCA activate M3R and that this activation is important for colon cancer progression $[41,42]$. In the current investigation, we have also found M3R expression to be greatly elevated in response to bile acids and that this increase is accompanied by a concomitant rise in the expression of MMP-1, MMP3, and MMP10 mRNA in HCoEpiC. MMPs are not only important in maintaining extracellular homeostasis but also play a prominent role in cancer cell invasion. Overexpression of MMP1, MMP2, MMP3, MMP7, MMP9, and MMP13 correlates with worse outcomes in cancer patients [26, 63-66].

Our observation that DCA or LCA could stimulate the expression of M3R in normal human colonic epithelial cells and that this induction is greatly attenuated when M3R is downregulated in colonic epithelial cells further supports a role for M3R in regulating DCA/LCA-mediated modulation of colon carcinogenesis. Additional support for this inference comes from the observation that DCA-mediated induction of $\mathrm{Wnt} / \beta$-catenin signaling in M3R-downregulated colonic epithelial cells, a prerequisite for colon carcinogenesis $[67,68]$, is greatly diminished.

\section{Conclusions}

Taken together, our current data show that certain secondary bile acids, specifically DCA and LCA, which are known for their co-carcinogenic activity, are able to induce CSCs in colonic epithelial cells. This is evidenced by the observation that DCA or LCA are not only able to stimulate the expression of several surface epitopes of colon CSCs but also the markers of EMT. These increases are associated with increased spheroid formation, a rise in the expression of multiple drug resistance transporter genes, and drug exclusion. DCA/LCA induction of colon carcinogenesis is found to be regulated by M3R. 


\section{Acknowledgements}

Not applicable.

\section{Funding}

This study was supported by grants to APNM from the NIH (1R21CA175916), the Department of Veteran Affairs (1101BX001927), and the Metropolitan Detroit Research and Education Fund (MDREF). The funders had no role in study design, data collection and analysis, decision to publish, or preparation of the manuscript.

\section{Availability of supporting data}

Not applicable

\section{Authors' contributions}

LF designed and performed experiments, acquired, analyzed and interpreted the data, and wrote the initial manuscript. PN-M performed experiments and reviewed the manuscript. EA and KS performed experiments and analyzed the data. SS and HM provided laboratory support and performed experiments. TH provided laboratory support and reviewed the manuscript. YY provided laboratory and material support and reviewed the manuscript. APNM, principal investigator, conceptualized the study, revised the manuscript, and approved the final version. All authors reviewed and approved the manuscript.

\section{Competing interests}

The authors declare that they have no competing interests.

\section{Consent for publication}

All authors.

\section{Ethical approval and consent to participate}

Not applicable.

\section{Author details}

'Department of Veterans' Affairs Medical Center, 4646 John R, Detroit, MI 48201, USA. ${ }^{2}$ Karmanos Cancer Institute, Detroit, MI 48201, USA. ${ }^{3}$ Department of Internal Medicine, Wayne State University, Detroit, MI 48201, USA.

Received: 26 August 2016 Revised: 26 October 2016 Accepted: 10 November 2016

Published online: 01 December 2016

\section{References}

1. Fiorucci S, Cipriani S, Baldelli F, Mencarelli A. Bile acid-activated receptors in the treatment of dyslipidemia and related disorders. Prog Lipid Res. 2010:49:171-85.

2. Hill MJ. Bile flow and colon cancer. Mutat Res. 1990;238:313-20.

3. Narisawa T, Magadia NE, Weisburger JH, Wynder EL. Promoting effect of bile acids on colon carcinogenesis after intrarectal instillation of $\mathrm{N}$-methyl- $\mathrm{N}$ '-nitro-N-nitrosoguanidine in rats. J Natl Cancer Inst. 1974:53:1093-7.

4. Plotnikoff GA. Three measurable and modifiable enteric microbial biotransformations relevant to cancer prevention and treatment. Glob Adv Health Med. 2014:3:33-43.

5. Ajouz H, Mukherji D, Shamseddine A. Secondary bile acids: an underrecognized cause of colon cancer. World J Surg Oncol. 2014;12:164.

6. Payne CM, Bernstein C, Dvorak K, Bernstein H. Hydrophobic bile acids, genomic instability, Darwinian selection, and colon carcinogenesis. Clin Exp Gastroenterol. 2008;1:19-47.

7. Payne CM, Crowley-Skillicorn C, Bernstein C, Holubec $\mathrm{H}_{\text {, Moyer MP, }}$ Bernstein $\mathrm{H}$. Hydrophobic bile acid-induced micronuclei formation, mitotic perturbations, and decreases in spindle checkpoint proteins: relevance to genomic instability in colon carcinogenesis. Nutr Cancer. 2010;62:825-40.

8. Prasad AR, Prasad S, Nguyen H, Facista A, Lewis C, Zaitlin B, et al. Novel dietrelated mouse model of colon cancer parallels human colon cancer. World J Gastrointest Oncol. 2014;6:225-43.

9. Maskarinec $\mathrm{G}$, Noh JJ. The effect of migration on cancer incidence among Japanese in Hawaii. Ethn Dis. 2004;14:431-9.

10. Kono S, Toyomura K, Yin G, Nagano J, Mizoue T. A case-control study of colorectal cancer in relation to lifestyle factors and genetic polymorphisms: design and conduct of the Fukuoka colorectal cancer study. Asian Pac J Cancer Prev. 2004;5:393-400.
11. Crowther JS, Drasar BS, Hill MJ, Maclennan R, Magnin D, Peach S, et al. Faecal steroids and bacteria and large bowel cancer in Hong Kong by socio-economic groups. Br J Cancer. 1976;34:191-8.

12. Reddy BS, Wynder EL. Large-bowel carcinogenesis: fecal constituents of populations with diverse incidence rates of colon cancer. J Natl Cancer Inst. 1973:50:1437-42.

13. Hofmann AF. Detoxification of lithocholic acid, a toxic bile acid: relevance to drug hepatotoxicity. Drug Metab Rev. 2004;36:703-22.

14. Clevers $\mathrm{H}$. The cancer stem cell: premises, promises and challenges. Nat Med. 2011:17:313-9

15. Choi D, Lee HW, Hur KY, Kim JJ, Park GS, Jang SH, et al. Cancer stem cell markers CD133 and CD24 correlate with invasiveness and differentiation in colorectal adenocarcinoma. World J Gastroenterol. 2009;15:2258-64.

16. Horst D, Scheel SK, Liebmann S, Neumann J, Maatz S, Kirchner T, et al. The cancer stem cell marker CD133 has high prognostic impact but unknown functional relevance for the metastasis of human colon cancer. J Pathol. 2009;219:427-34.

17. Langan RC, Mullinax JE, Ray S, Raiji MT, Schaub N, Xin HW, et al. A pilot study assessing the potential role of non-CD133 colorectal cancer stem cells as biomarkers. J Cancer. 2012;3:231-40.

18. Ribeiro KB, da Silva ZJ, Ribeiro-Silva A, Rapatoni L, de Oliveira HF, da Cunha Tirapelli DP, et al. KRAS mutation associated with CD44/CD166 immunoexpression as predictors of worse outcome in metastatic colon cancer. Cancer Biomark. 2016;16:513-21.

19. O'Brien CA, Pollett A, Gallinger S, Dick JE. A human colon cancer cell capable of initiating tumour growth in immunodeficient mice. Nature. 2007:445:106-10

20. Bernstein H, Bernstein C, Payne CM, Dvorak K. Bile acids as endogenous etiologic agents in gastrointestinal cancer. World J Gastroenterol. 2009; 15:3329-40.

21. Burnat G, Majka J, Konturek PC. Bile acids are multifunctional modulators of the Barrett's carcinogenesis. J Physiol Pharmacol. 2010;61:185-92.

22. Louis P, Hold GL, Flint HJ. The gut microbiota, bacterial metabolites and colorectal cancer. Nat Rev Microbiol. 2014;12:661-72.

23. Stallmach A, von Lampe B, Matthes $H$, Bornhoft G, Riecken EO. Diminished expression of integrin adhesion molecules on human colonic epithelial cells during the benign to malign tumour transformation. Gut. 1992:33:342-6.

24. Mayer L, Eisenhardt D, Salomon P, Bauer W, Plous R, Piccinini L. Expression of class II molecules on intestinal epithelial cells in humans. Differences between normal and inflammatory bowel disease. Gastroenterology. 1991;100:3-12.

25. Eckmann L, Jung HC, Schurer-Maly C, Panja A, Morzycka-Wroblewska E, Kagnoff MF. Differential cytokine expression by human intestinal epithelial cell lines: regulated expression of interleukin 8. Gastroenterology. 1993;105: 1689-97.

26. Xie G, Cheng K, Shant J, Raufman JP. Acetylcholine-induced activation of M3 muscarinic receptors stimulates robust matrix metalloproteinase gene expression in human colon cancer cells. Am J Physiol Gastrointest Liver Physiol. 2009;296:G755-63.

27. Farhana L, Antaki F, Anees MR, Nangia-Makker P, Judd S, Hadden T, et al. Role of cancer stem cells in racial disparity in colorectal cancer. Cancer Med. 2016; 5 1268-78.

28. Leavell BJ, Van Buren E, Antaki F, Axelrod BN, Rambus MA, Majumdar AP. Associations between markers of colorectal cancer stem cells and adenomas among ethnic groups. Dig Dis Sci. 2012;57:2334-9.

29. Kanwar SS, Yu Y, Nautiyal J, Patel BB, Padhye S, Sarkar FH, et al. Difluorinated-curcumin (CDF): a novel curcumin analog is a potent inhibitor of colon cancer stem-like cells. Pharm Res. 2011;28:827-38.

30. Farhana L, Dawson MI, Fontana JA. Apoptosis induction by a novel retinoidrelated molecule requires nuclear factor-kappaB activation. Cancer Res. 2005:65:4909-17.

31. Muller M, Hermann PC, Liebau S, Weidgang C, Seufferlein T, Kleger A, et al. The role of pluripotency factors to drive stemness in gastrointestinal cancer. Stem Cell Res. 2016;16:349-57.

32. Abad M, Mosteiro L, Pantoja C, Canamero M, Rayon T, Ors l, et al. Reprogramming in vivo produces teratomas and iPS cells with totipotency features. Nature. 2013:502:340-5.

33. Maherali N, Sridharan R, Xie W, Utikal J, Eminli S, Arnold K, et al. Directly reprogrammed fibroblasts show global epigenetic remodeling and widespread tissue contribution. Cell Stem Cell. 2007;1:55-70. 
34. Ohnishi K, Semi K, Yamada Y. Epigenetic regulation leading to induced pluripotency drives cancer development in vivo. Biochem Biophys Res Commun. 2014;455:10-5.

35. Takahashi K, Okita K, Nakagawa M, Yamanaka S. Induction of pluripotent stem cells from fibroblast cultures. Nat Protoc. 2007;2:3081-9.

36. Takahashi K, Yamanaka S. Induction of pluripotent stem cells from mouse embryonic and adult fibroblast cultures by defined factors. Cell. 2006;126: 663-76.

37. Nakajima S, Doi R, Toyoda E, Tsuji S, Wada M, Koizumi M, et al. N-cadherin expression and epithelial-mesenchymal transition in pancreatic carcinoma. Clin Cancer Res. 2004;10:4125-33.

38. Tran DD, Corsa CA, Biswas H, Aft RL, Longmore GD. Temporal and spatial cooperation of Snail1 and Twist1 during epithelial-mesenchymal transition predicts for human breast cancer recurrence. Mol Cancer Res. 2011;9:1644-57.

39. Vandewalle C, Comijn J, De Craene B, Vermassen P, Bruyneel E, Andersen H, et al. SIP1/ZEB2 induces EMT by repressing genes of different epithelial cellcell junctions. Nucleic Acids Res. 2005;33:6566-78.

40. Fletcher J, Haber M, Henderson MJ, Norris MD. ABC transporters in cancer: more than just drug efflux pumps. Nat Rev Cancer. 2010;10:147-56.

41. Cheng $K$, Chen Y, Zimniak P, Raufman JP, Xiao Y, Frucht H. Functional interaction of lithocholic acid conjugates with M3 muscarinic receptors on a human colon cancer cell line. Biochim Biophys Acta. 2002;1588:48-55.

42. Cheng K, Raufman JP. Bile acid-induced proliferation of a human colon cancer cell line is mediated by transactivation of epidermal growth factor receptors. Biochem Pharmacol. 2005;70:1035-47.

43. Kanwar SS, Yu Y, Nautiyal J, Patel BB, Majumdar AP. The Wnt/beta-catenin pathway regulates growth and maintenance of colonospheres. Mol Cancer. 2010:9:212.

44. Korinek V, Barker N, Moerer P, van Donselaar E, Huls G, Peters PJ, et al. Depletion of epithelial stem-cell compartments in the small intestine of mice lacking Tcf-4. Nat Genet. 1998;19:379-83.

45. Vermeulen L, De Sousa EMF, van der Heijden M, Cameron $K$, de Jong JH, Borovski T, et al. Wnt activity defines colon cancer stem cells and is regulated by the microenvironment. Nat Cell Biol. 2010;12:468-76.

46. Katoh M, Katoh M. WNT signaling pathway and stem cell signaling network. Clin Cancer Res. 2007;13:4042-5.

47. Logan CY, Nusse R. The Wnt signaling pathway in development and disease. Annu Rev Cell Dev Biol. 2004;20:781-810.

48. He TC, Sparks AB, Rago C, Hermeking H, Zawel L, da Costa LT, et al. Identification of c-MYC as a target of the APC pathway. Science. 1998;281: 1509-12.

49. Rennoll S, Yochum G. Regulation of MYC gene expression by aberrant Wnt/ beta-catenin signaling in colorectal cancer. World J Biol Chem. 2015;6:290-300.

50. Cheng K, Xie G, Raufman JP. Matrix metalloproteinase-7-catalyzed release of HB-EGF mediates deoxycholyltaurine-induced proliferation of a human colon cancer cell line. Biochem Pharmacol. 2007;73:1001-12.

51. Cheng K, Zimniak P, Raufman JP. Transactivation of the epidermal growth factor receptor mediates cholinergic agonist-induced proliferation of $\mathrm{H} 508$ human colon cancer cells. Cancer Res. 2003;63:6744-50.

52. Armstrong B, Doll R. Environmental factors and cancer incidence and mortality in different countries, with special reference to dietary practices. Int J Cancer. 1975;15:617-31.

53. Kundu S, Kumar S, Bajaj A. Cross-talk between bile acids and gastrointestinal tract for progression and development of cancer and its therapeutic implications. IUBMB Life. 2015;67:514-23.

54. Rogers AE, Zeisel SH, Groopman J. Diet and carcinogenesis. Carcinogenesis. 1993:14:2205-17.

55. Armstrong B, Doll R. Bladder cancer mortality in diabetics in relation to saccharin consumption and smoking habits. Br J Prev Soc Med. 1975;29:73-81.

56. Bayerdorffer E, Mannes GA, Ochsenkuhn T, Dirschedl P, Wiebecke B, Paumgartner $\mathrm{G}$. Unconjugated secondary bile acids in the serum of patients with colorectal adenomas. Gut. 1995;36:268-73.

57. Rosignoli P, Fabiani R, De Bartolomeo A, Fuccelli R, Pelli MA, Morozzi G. Genotoxic effect of bile acids on human normal and tumour colon cells and protection by dietary antioxidants and butyrate. Eur J Nutr. 2008;47:301-9.

58. Delzenne NM, Calderon PB, Taper HS, Roberfroid MB. Comparative hepatotoxicity of cholic acid, deoxycholic acid and lithocholic acid in the rat: in vivo and in vitro studies. Toxicol Lett. 1992;61:291-304.

59. Song $P$, Zhang $Y$, Klaassen CD. Dose-response of five bile acids on serum and liver bile Acid concentrations and hepatotoxicty in mice. Toxicol Sci. 2011;123:359-67.
60. Sousa T, Castro RE, Pinto SN, Coutinho A, Lucas SD, Moreira R, et al. Deoxycholic acid modulates cell death signaling through changes in mitochondrial membrane properties. J Lipid Res. 2015;56:2158-71.

61. Woolbright BL, McGill MR, Yan H, Jaeschke H. Bile Acid-Induced Toxicity in HepaRG Cells Recapitulates the Response in Primary Human Hepatocytes. Basic Clin Pharmacol Toxicol. 2016;118:160-7.

62. Andersen V, Svenningsen K, Knudsen LA, Hansen AK, Holmskov U, Stensballe $A$, et al. Novel understanding of $A B C$ transporters $A B C B 1 / M D R / P$ glycoprotein, $A B C C 2 / M R P 2$, and $A B C G 2 / B C R P$ in colorectal pathophysiology. World J Gastroenterol. 2015;21:11862-76.

63. Belo A, Cheng K, Chahdi A, Shant J, Xie G, Khurana S, et al. Muscarinic receptor agonists stimulate human colon cancer cell migration and invasion. Am J Physiol Gastrointest Liver Physiol. 2011;300:G749-60.

64. Raufman JP, Cheng K, Saxena N, Chahdi A, Belo A, Khurana S, et al. Muscarinic receptor agonists stimulate matrix metalloproteinase 1dependent invasion of human colon cancer cells. Biochem Biophys Res Commun. 2011:415:319-24.

65. Said AH, Raufman JP, Xie G. The role of matrix metalloproteinases in colorectal cancer. Cancers (Basel). 2014;6:366-75.

66. Zucker S, Vacirca J. Role of matrix metalloproteinases (MMPs) in colorectal cancer. Cancer Metastasis Rev. 2004;23:101-17.

67. Flynn C, Montrose DC, Swank DL, Nakanishi M, Ilsley JN, Rosenberg DW. Deoxycholic acid promotes the growth of colonic aberrant crypt foci. Mol Carcinog. 2007:46:60-70.

68. Pai R, Tarnawski AS, Tran T. Deoxycholic acid activates beta-catenin signaling pathway and increases colon cell cancer growth and invasiveness. Mol Biol Cell. 2004;15:2156-63.

\section{Submit your next manuscript to BioMed Central and we will help you at every step:}

- We accept pre-submission inquiries

- Our selector tool helps you to find the most relevant journal

- We provide round the clock customer support

- Convenient online submission

- Thorough peer review

- Inclusion in PubMed and all major indexing services

- Maximum visibility for your research

Submit your manuscript at www.biomedcentral.com/submit
) Biomed Central 